\title{
HUBUNGAN PENDAPATAN ORANGTUA DAN POLA MAKAN SERTA KEJADIAN PENYAKIT DIARE DENGAN STATUS GIZI
}

\author{
Asmiati ${ }^{1}$, Rudy Hartono ${ }^{1}$, Aswita Amir ${ }^{1}$, Hijrah Asikin ${ }^{1}$ \\ Jurusan Gizi, Politeknik Kesehatan Kemenkes Makassar
}

\begin{abstract}
This type of research is analytic research using the Cross-Sectional Study approach, to obtain data on the relationship of diet and parental income and the incidence of diarrheal diseases on nutritional status (BB / TB) of the students of SDN Daya 1. Populations in this study were all elementary school students of the third, fourth, and fifth grade of SDN Daya 1 Makassar City. The sample in this study were elementary school students in the grades III, IV and V in SDN Daya 1 located in Paccerakkang village, Biringkanaya Subdistrict, Makassar City, with the following criteria: class III-V students who were willing to become a sample; children are in good health at the time of sampling; and parents and teachers are willing to become respondents. Data analysis uses the Chi-Square test. The results showed that diet was not related to nutritional status as evidenced by the value of $p=0.48$ ( $>$ $0.05)$, parental income was not related to nutritional status where most of the parents' income level was quite sufficient as evidenced by $p=0,269>0.05$ ) as well as the incidence of diarrhea not related to nutritional status as evidenced by $p=0.470$ (>0.05). It is recommended that the process of data collection is better collaboration between researchers and the school, making direct observations at the household level regarding food availability, and adding food intake variables to find out the meal portion of the sample.
\end{abstract}

Keywords: Parental Income, Diet, Diarrhea and Nutritional Status

\section{PENDAHULUAN}

Keberhasilan pembangunan nasional suatu bangsa ditentukan oleh ketersediaan Sumber Daya Manusia (SDM) yang berkualitas, yaitu SDM yang memiliki fisik yang tangguh, mental yang kuat dan kesehatan yang prima serta cerdas. Pada kenyataannya kualitas SDM ditentukan oleh status gizi yang baik (Adriani, 2013).

Masalah gizi pada hakikatnya adalah masalah kesehatan masyarakat, namun penanggulangannya tidak dapat dilakukan dengan pendekatan medis dan pelayanan kesehatan saja. Masalah munculnya gizi kurang dapat dipengaruhi oleh beberapa faktor diantaranya adalah akibat masalah ketahanan pangan di tingkat rumah tangga, yaitu kemampuan rumah tangga memperoleh makanan untuk semua anggota keluarganya (Supariasa, 2014).

Tiga faktor yang mempengaruhi kejadian gizi buruk secara langsung, yaitu: anak tidak cukup mendapat makanan bergizi seimbang, anak tidak mendapat asupan gizi yang memadai dan anak mungkin menderita penyakit infeksi (Dinkes, 2009). Besar kecilnya asupan zat gizi tergantung pada apa yang terkandung dalam makanan yang dikonsumsi. Pemenuhan gizi dalam keluarga tidak telepas dari pendapatan orang tua sebagai sumber dana yang utama (Farida, 2004).
Anak-anak sekolah dasar merupakan salah satu kelompok yang rawan mengalami gizi kurang diantara penyebabnya ialah tingkat ekonomi yang rendah dan asupan makanan yang kurang seimbang serta rendahnya pengetahuan orang tua. Anak sekolah dengan pola makan seimbang cenderung memiliki status gizi yang baik. Menurut Riset Kesehatan Dasar tahun 2014, penduduk yang mengkonsumsi makanan di bawah $70 \%$ dari Angka Kecukupan Gizi (AKG) yang dianjurkan tahun 2004 sebanyak 40,6\%. Keadaan ini banyak dijumpai pada anak usia sekolah $(41,2 \%)$, remaja $(54,5 \%)$, dan ibu hamil $(44,2 \%)$.

Asupan zat gizi berpengaruh pada status gizi seseorang. Status gizi baik atau optimal terjadi bila tubuh memperoleh zat-zat gizi yang digunakan secara efisien, sehingga memungkinkan pertumbuhan fisik, perkembangan otak, kemampuan kerja dan kesehatan secara umum pada tingkat setinggi mungkin (Almatsier, 2004).

Insidensi penyakit diare di Indonesia untuk seluruh kelompok umur tahun 2013 adalah $3,5 \%$ dan angka prevalensi sebesar $7,0 \%$. Sedangkan insidensi dan prevalensi penyakit diare di Indonesia pada tahun 2013 untuk kelompok umur 6 -14 tahun adalah 3,0\% dan $6,2 \%$. anak sekolah dasar adalah anak-anak yang berusia 7-12 tahun memiliki fisik lebih kuat, mempunyai sifat individual serta aktif dan tidak bergantung kepada orang tua. Usia sekolah merupakan masa anak memperoleh 
dasar-dasar pengetahuan untuk keberhasilan penyesuaian diri pada kehidupan dewasa dan memperoleh keterampilan tertentu. Anak usia sekolah dasar berada dalam tahap pertumbuhan dan perkembangan sehingga mudah untuk dibimbing, diarahkan, dan ditanamkan kebiasaan-kebiasaan baik.

Berdasarkan penemuan kasus diare di Sulawesi Selatan tahun 2016 perkiraan diare di fasilitas kesehatan sebanyak 230.048 kasus. sedangkan penderita diare yang ditangani sebanyak 172.650 kasus.

Masalah gizi yang terdapat di Indonesia diantaranya kecenderungan prevalensi kurus pada anak sekolah mencapai $28,5 \%$ (Riskesdas, 2010). Angka gizi kurang dan gizi buruk tingkat Sulawesi Selatan tahun 2009 yang mencapai 20.5\%. Data tahun 2014 yang dihimpun Bidang P2PL (Pengendalian Penyakit dan Penyehatan Lingkungan) mencatat jumlah penderita diare yang ditemukan dan ditangani sebanyak 12.600 kasus $(96,26 \%)$ dengan angka kesakitan sebesar 31,12 per 1.000 penduduk.

Rendahnya Indeks Pembangunan Manusia (IPM) di Indonesia sangat dipengaruhi oleh rendahnya status gizi dan kesehatan penduduk (Dinkes, 2009). Gizi yang baik adalah gizi yang seimbang, artinya asupan zat gizi harus sesuai dengan kebutuhan tubuh.

Tujuan umum penelitian untuk mengetahui hubungan pendapatan orang tua, pola makan serta kejadian penyakit infeksi dengan status gizi anak SDN Daya 1.

\section{METODE}

\section{Desain, tempat dan waktu}

Jenis penelitian ini adalah penelitian analitik dengan menggunakan pendekatan Cross Sectional Study, untuk memperoleh data mengenai hubungan pola makan dan pendapatan orang tua serta kejadian penyakit diare terhadap status gizi (BB/TB) anak SDN Daya 1. Penelitian ini dilakukan di SDN Daya 1 Kelurahan Paccerakkang Kecamatan Biringkanaya Kota Makassar. Penelitian ini dimulai pada bulan Februari 2018 - April 2018
Jumlah dan cara pengambilan subjek

Populasi dalam penelitian ini adalah semua anak sekolah Dasar kelas III, IV, dan V di SDN Daya 1 di Kelurahan Paccerakkang Kec.Biringkanaya Kota Makassar.

\section{Jenis dan Cara Pengumpulan Data}

1. Data Primer

Data yang dikumpulkan adalah tingkat pendapatan keluarga, pola makan anak, serta kejadian penyakit infeksi yang mempengaruhi status gizi diperoleh dengan melakukan wawancara dan menggunakan kuesioner.

\section{Data Sekunder}

Data sekunder meliputi data geografi dan demografi yang diperoleh dari lokasi penelitian dan instansi yang terkait.

\section{Pengolahan dan analisis data}

Data yang dikumpulkan meliputi Berat badan dan umur anak dihitung menggunakan WHO-Antro, data sosial ekonomi diperoleh menggunakan kuesioner dan data pola makan diperoleh melalui kuesioner FFQ dan dihitung menggunakan Komputer Program Microsoft Excel 2007. Hasil perhitungan dikategorikan berdasarkan nilai rata-rata. Selanjutnya dianalisis menggunakan Program SPSS, untuk analisis Statistik menggunakan uji chi - square. Hasil analisis data disajikan dalam bentuk tabel dan narasi.

\section{HASIL}

Berdasarkan hasil penelitian diketahui bahwa orang tua siswa yang memiliki pendapatan cukup sebanyak 38 orang $(54,3 \%)$. Sedangkan yang memiliki pendapatan kurang sebanyak 32 orang $(45,7 \%)$.

Berdasarkan hasil penelitian pada umumnya dari 70 siswa yang pola makan baik sebanyak 28 siswa $(60 \%)$.

Berdasarkan hasil penelitian diketahui bahwa anak yang mengalami diare sebanyak 21 siswa (30\%), sedangkan anak yang tidak mengalami diare sebanyak 49 siswa (70\%). Berdasarkan penelitian pada umumnya anak memiliki status gizi normal sebanyak 60 orang $(85,7 \%)$.

Berdasarkan hasil distribusi Hubungan Pendapatan Orang Tua Dengan Status Gizi menunjukkan bahwa pada umumnya orang tua siswa yang memiliki pendapatan cukup dengan status gizi normal sebanyak 34 $(48,6 \%)$. Hasil analisis chi square diketahui 
tidak ada hubungan tingkat pendapatan orang tua terhadap status gizi dengan signifikan $p=0,262(>0,05)$.

Berdasarkan hasil distribusi Hubungan Pola Makan Dengan Status Gizi menunjukkan pola makan anak yang kurang sebanyak 60,0 $\%$ dengan status gizi Normal sebanyak 52,9 $\%$. Hasil analisis chi square diketahui tidak ada hubungan antara pola makan dengan status gizi anak dengan signifikan $p=0,486$ $(>0,05)$.

Berdasarkan hasil distribusi Hubungan Kejadian Diare Dengan Status Gizi menunjukkan bahwa pada umumnya anak yang mengalami diare dengan status gizi normal sebanyak 17 anak (24,3\%). Hasil analisis chi square diketahui tidak ada hubungan antara kejadian diare terhadap status gizi dengan signifikan $p=0,473(>0,05)$.

\section{PEMBAHASAN}

Berdasarkan penelitian yang dilakukan di SDN Daya 1 Kota Makassar menunjukan tidak terdapat hubungan antara pendapatan orang tua terhadap status gizi dimana hasil uji chi square nilai $p=0,262 \quad(>0,05)$. Pendapatan keluarga yang kurang dari UMR masih dapat mencukupi kebutuhan makanan keluarga sehingga status gizinya normal. Keadaan ekonomi keluarga yang baik belum tentu bisa menjamin ketersediaan pangan didalam rumah tangga. Berdasarkan hasil penelitian rata-rata pendapatan orang tua cukup sebanyak $38(54,3 \%)$, dengan status gizi normal sebanyak 34 (48,6\%). Pendapatan memang merupakan salah satu faktor penyebab status gizi kurang. tetapi pendapatan hanya merupakan penyebab tidak langsung terjadinya status gizi kurang. Sedangkan penyebab langsung nya adalah asupan dan adanya penyakit infeksi.

Status gizi yang kurang mencerminkan ketidakseimbangan dalam asupan makanan atau penyakit menular. Hal tersebut dipengaruhi oleh faktor lingkungan dan sosial ekonomi, seperti status ekonomi rumah tangga, pendidikan ibu, kebersihan rumah tangga, dan akses dalam pelayanan kesehatan (Pongou dkk, 2006). Penyebab tidak langsung diantaranya adalah ketahanan pangan didalam keluarga, pola pengasuhan anak, pelayanan kesehatan,serta kesehatan lingkungan (Istiono, 2009).
Berdasarkan hasil penelitian dengan melihat pola makan anak menggunakan food frequency Questionnaire (FFQ) dari 70 siswa didapatkan hasil sampel yang pola makan rendah sebanyak 42 sampel dan sampel yang pola makan baik sebanyak 28 sampel. Dimana didapatkan tidak terdapat hubungan antara pola makan anak dengan status gizi dengan nilai $p=0,486$. Hasil penelitian ini sejalan dengan penelitian yang dilakukan oleh Faradiba tahun 2012 bahwa tidak terdapat hubungan signifikan antara pola makan dengan status gizi pada anak usia pra sekolah di wilayah Puskesmas Samata Kabupaten Gowa dimana hasil uji chi- square nilai $p=0,473$ jauh diatas nilai alpha yang berarti tidak ada hubungan.

Meskipun pola makan anak kurang tidak menutup kemungkinan anak akan memiliki status gizi baik. Dalam konsumsi makanan (pola makan) yang diberikan oleh orang tua anak, meskipun misalnya hanya dua kali dalam sehari tetapi komposisi bahan makanan, dan pola hidangan mengandung unsur-unsur gizi yang dibutuhkan oleh tubuh anak, yakni sumber zat tenaga (nasi,roti,gula, dan lain-lain), sumber zat pembangun misalnya (ikan,daging,telur, dan lain-lain), serta zat pengatur seperti (sayur, buahbuahan) pola makan seperti inilah yang akan membuat anak memiliki status gizi yang baik. Berdasarkan penelitian diinterpretasikan sebanyak $42(60,0 \%)$ anak dengan pola makan kurang justru memiliki status gizi normal. Hal ini bisa disebabkan oleh berbagai faktor dengan mengetahui bagaimana cara konsumsi makan pada anak, tingkat kemampuan keluarga dalam menyediakan makanan masih rendah, dan keadaan ekonomi keluarga disertai dengan pendidikan gizi dan kesehatan.

Berdasarkan penelitian yang dilakukan di SDN Daya 1 Kota Makassar didapatkan hasil bahwa anak yang mengalami diare sebanyak $17(24,3 \%)$ dengan status gizi normal dan status gizi kurus sebanyak $4 \quad(5,7 \%)$. sedangkan, yang tidak mengalami diare sebanyak $43(61,4 \%)$ dengan status gizi normal dan status gizi kurus sebanyak 6 $(8,6 \%)$. Hasil penelitian dilakukan dengan menggunakan uji chi square dan didapatkan nilai $p=0,473$ yang menyatakan tidak adanya hubungan antara kejadian diare terhadap status gizi. Hal ini sejalan dengan penelitian yang dilakukan oleh Fahmi tahun 2013 
menyatakan tidak adanya hubungan antara status gizi dengan kejadian diare. Dimana status gizi yang kurang memiliki peluang besar terkena diare dibandingkan yang status gizi baik.

Menurut Nuryanto tahun 2012 bahwa status gizi yang baik umumnya akan meningkatkan resistensi tubuh terhadap penyakit-penyakit infeksi. kejadian diare juga dapat terjadi karena asupan yang tidak seimbang, pola makan yg kurang baik serta adanya kontaminasi terhadap makanan yang menyebabkan terjadinya diare. Kejadian diare tidak berpengaruh terhadap status gizi karena sistem kekebalan tubuh setiap anak berbeda-beda sehingga ada yang mengalami diare tetapi status gizi nya masih normal namun ada juga yg mengalami diare dengan secara langsung dapat mempengaruhi status gizinya menjadi status gizi kurang.

\section{KESIMPULAN}

Berdasarkan hasil penelitian diketahui bahwa tidak terdapat Hubungan antara Pendapatan Orangtua Dan Pola Makan Serta Kejadian Penyakit Diare Dengan Status Gizi Di SDN Daya 1 Kota Makassar.

\section{SARAN}

penelitian selanjutnya diharapkan agar melakukan penelitian observasi langsung di tingkat rumah tangga mengenai ketersediaan pangan keluarga dengan memperhatikan pendapatan keluarga (orang tua).

1. Teristimewa, penulis menghaturkan terima kasih kepada seluruh keluarga khususnya Ayah, Ibu serta kakak atas segala doa dan pengorbanan yang diberikan, baik moril maupun material.

2. Terkhusus, sahabat-sahabat dan teman-teman yang telah memberikan motivasi dan menemaniku dalam susah maupun senang dalam penyusunan Skripsi ini.

\section{DAFTAR PUSTAKA}

Adriani \& Bambang. (2013). Pengantar Gizi Masyarakat. Jakarta; Kencana Prenada Media Group.

Almatsier (2004). PrinsipdasarllmuGizi. Jakarta; PT Gramedia Pustaka Utama.

Dinkes kota Makassar, 2009. Faktor- Faktor Penyebab Masalah Gizi.

Farida, 2004. Pengantar Pangan dan Gizi. Penebar Swadaya: Jakarta.

Fahmi (2013), Hubungan Status Gizi Dengan Kejadian Diare Pada Balita Usia 2-5 Tahun Diwilayah Kerja Puskesmas Kecamatan Karanganyar Kabupaten Karanganyar. Fakultas Kedokteran Universitas Muhammadiyah Surakarta.

Istiono,W dkk (2009). Analisis Faktor-Faktor Yang Mempengaruhi Status Gizi Balita. Berita kedokteran Masyarakat.

Nuryanto (2012), Hubungan Status Gizi Terhadap Terjadinya Penyakit Infeksi Saluran Pernafasan Akut (ISPA) Pada Balita. Jurnal Pembangunan Manusia

Pongou, dkk (2006). BMC Public Health 2006 6:98. House And Community Socioeconomic And Enveronniental Determinants of Chid Nutritional Status In Cameroon. Di unduh dari (diakses 12 juli 2018)

Supariasa N, Bakri B, Fajar I. (2014). Penilaian Status Gizi. Jakarta; Buku Kedokteran ECG.

Tabel 1

Distribusi Sampel Berdasarkan Jenis Kelamin di SDN

Daya 1 Kecamatan Biringkanaya

Kota Makassar 


\begin{tabular}{ccc}
\hline \hline Jenis kelamin & n' $^{\prime}$ & $\%$ \\
\hline Laki-laki & 25 & 35,7 \\
perempuan & 45 & 64,3 \\
\hline Total & 70 & 100
\end{tabular}

Tabel 2

Distribusi Sampel Berdasarkan Umur di SDN Daya 1 Kecamatan Biringkanaya Kota Makassar

\begin{tabular}{ccc}
\hline \hline Umur Sampel (Tahun) & $\mathrm{n}$ & $\%$ \\
\hline $8-9$ tahun & 26 & 37,14 \\
$10-11$ tahun & 42 & 59,9 \\
$12-13$ tahun & 2 & 2,84 \\
\hline Total & 70 & 100 \\
\hline
\end{tabular}

Sumber: Data Primer 2018

Tabel 3

Distribusi Sampel Berdasarkan Pekerjaan Ayah di SDN Daya 1 Kecamatan Biringkanaya Kota Makassar

\begin{tabular}{lcc}
\hline \hline Pekerjaan Ayah & $\mathrm{n}$ & $\%$ \\
& & \\
\hline PNS & 3 & 4,2 \\
Karyawan swasta & 45 & 64,2 \\
Pedagang & 7 & 10 \\
Buruh & 11 & 15,7 \\
Supir & 2 & 2,8 \\
Tukang parkir & 1 & 1,4 \\
Tidak bekerja & 1 & 1,4 \\
Total & 70 & 100
\end{tabular}

Sumber: Data Primer 2018

Tabel 4

Distribusi Sampel Berdasarkan Pekerjaan Ibu di SDN Daya 1 Kecamatan Biringkanaya

Kota Makassar

\begin{tabular}{lcc}
\hline \multicolumn{1}{c}{ Pekerjaan Ibu } & $\mathrm{n}$ & $\%$ \\
\hline Wiraswasta & 9 & 12,9 \\
Buruh & 1 & 1,4 \\
PNS & 5 & 7,1 \\
Pedagang & 7 & 10,0 \\
IRT & 48 & 68,6 \\
\hline Total & 70 & 100
\end{tabular}

Sumber: Data Primer 2018

Tabel 5

Distribusi Pendapatan Orang Tua Anak SDN Daya 1

Kecamatan Biringkanaya

Kota Makassar 


\begin{tabular}{|c|c|c|}
\hline Pendapatan orang tua & $\mathrm{n}$ & $\%$ \\
\hline Cukup & 38 & 54,3 \\
\hline Kurang & 32 & 45,7 \\
\hline Total & 70 & 100 \\
\hline \multicolumn{3}{|c|}{ Sumber: Data Primer 2018} \\
\hline \multicolumn{3}{|c|}{$\begin{array}{c}\text { Tabel } 6 \\
\begin{array}{c}\text { Distribusi Pola Makan Anak SDN Daya } 1 \\
\text { Kecamatan Biringkanaya } \\
\text { Kota Makassar }\end{array}\end{array}$} \\
\hline Pola Makan & $\mathrm{n}$ & $\%$ \\
\hline Baik & 28 & 40 \\
\hline Kurang & 42 & 60 \\
\hline Total & 70 & 100 \\
\hline
\end{tabular}

Tabel 7

Distribusi Kejadian Diare Anak SDN Daya 1

Kecamatan Biringkanaya

Kota Makassar

\begin{tabular}{ccc}
\hline \hline Kejadian Diare & $\mathrm{n}$ & $\%$ \\
\hline Ya & 21 & 30 \\
Tidak & 49 & 70 \\
\hline Total & 70 & 100 \\
\hline
\end{tabular}

Sumber: Data Primer 2018

Tabel 8

Distribusi Status gizi BB/TB Anak SDN Daya 1

Kecamatan Biringkanaya

Kota Makassar

\begin{tabular}{ccc}
\hline Status Gizi & n' & $\%$ \\
& & \\
\hline Normal & 60 & 85,7 \\
Kurus & 10 & 14,3 \\
\hline Total & 70 & 100 \\
\hline
\end{tabular}


Tabel 9

Distribusi Pendapatan Orang Tua dengan Status Gizi Anak SDN Daya 1 Kecamatan Biringkanaya

Kota Makassar

\begin{tabular}{|c|c|c|c|c|c|c|c|}
\hline \multirow{3}{*}{$\begin{array}{c}\text { Pendapatan } \\
\text { Orang tua }\end{array}$} & \multicolumn{6}{|c|}{ Status Gizi } & \multirow{3}{*}{$\begin{array}{c}P \\
\text { Value }\end{array}$} \\
\hline & \multicolumn{2}{|c|}{ Normal } & \multicolumn{2}{|c|}{ Kurus } & \multicolumn{2}{|c|}{ Total } & \\
\hline & $\mathrm{n}$ & $\%$ & $\mathrm{n}$ & $\%$ & $\mathrm{n}^{\prime}$ & $\%$ & \\
\hline Cukup & 34 & 48,6 & 4 & 5,7 & 38 & 54,3 & \\
\hline Rendah & 26 & 37,1 & 6 & 8,6 & 32 & 45,7 & 0,262 \\
\hline Total & 60 & 85,7 & 10 & 14,3 & 70 & 100 & \\
\hline
\end{tabular}

Sumber: Data Primer 2018

Tabel 10

Distribusi Pola Makan dengan Status Gizi Anak SDN Daya 1 Kecamatan Biringkanaya

Kota Makassar

\begin{tabular}{|c|c|c|c|c|c|c|c|}
\hline \multirow{3}{*}{ Pola Makan } & \multicolumn{6}{|c|}{ Status Gizi } & \multirow{3}{*}{$\begin{array}{c}P \\
\text { Value }\end{array}$} \\
\hline & \multicolumn{2}{|c|}{ Normal } & \multicolumn{2}{|c|}{ Kurus } & \multicolumn{2}{|c|}{ Total } & \\
\hline & $\mathrm{n}$ & $\%$ & $\mathrm{n}$ & $\%$ & $\mathrm{n}$ & $\%$ & \\
\hline Baik & 23 & 3,9 & 5 & 7,1 & 28 & 40,0 & \\
\hline Kurang & 37 & 52,9 & 5 & 7,1 & 42 & 60,0 & 0,486 \\
\hline Total & 60 & 85,7 & 10 & 14,3 & 70 & 100 & \\
\hline
\end{tabular}

Sumber: Data Primer 2018

Tabel 11

Distribusi Kejadian Diare dengan Status Gizi Anak SDN Daya 1

Kecamatan Biringkanaya

Kota Makassar

\begin{tabular}{|c|c|c|c|c|c|c|c|}
\hline \multirow{3}{*}{ Kejadian Diare } & \multicolumn{6}{|c|}{ Status Gizi } & \multirow{3}{*}{ P Value } \\
\hline & \multicolumn{2}{|c|}{ Normal } & \multicolumn{2}{|c|}{ Kurus } & \multicolumn{2}{|c|}{ Total } & \\
\hline & $\mathrm{n}$ & $\%$ & $\mathrm{n}$ & $\%$ & $\mathrm{n}$ & $\%$ & \\
\hline Ya & 17 & 24,3 & 4 & 5,7 & 21 & 30,0 & \\
\hline Tidak & 43 & 61,4 & 6 & 8,6 & 49 & 70,0 & 0,473 \\
\hline Total & 60 & 85,7 & 10 & 14,3 & 70 & 100 & \\
\hline
\end{tabular}

Sumber: Data Primer 2018 